\title{
Spinnerets and silk-producing system of Segestria senoculata (Araneae, Araneomorphae, Segestriidae)
}

\author{
S. Karschová, J. Hajer \\ Department of Biology, J.E. Purkinje University, Ústí nad Labem, Czech Republic
}

\begin{abstract}
The spinning apparatus and silk of Segestria senoculata were studied with the use of scanning electron microscopy and light microscopy, which confirmed the presence of four categories of spigots connected with four types of spinning glands (i.e., Glandulae ampullaceae major, Glandulae ampullaceae minor, Glandulae piriformes and Glandulae pseudaciniformes). New data about the morphology of spinnerets and spigots were obtained for both the adults and nymphal stages of both sexes. For the first time the silken threads of retreats, signal threads and attachment discs of the members of Segestria were subjected to a detailed SEM study. The data resulting from studying the spinning apparatus of $S$. senoculata was compared to current knowledge of the silk producing systems of families belonging to the Dysderoidea superfamily. Silks that are emitted from spigots in the course of retreat construction are not (similarly to the other dysderoids) processed by the spider's legs during the subsequent process of hardening. Apart from the major ampullate glands/spigots, segestriids also possess developed minor ampullate glands. Minor ampullate threads are used by $S$. senoculata spiders when making their signal threads.
\end{abstract}

Correspondence: Jaromír Hajer, Department of Biology, Faculty of Science, J.E. Purkinje University in Ústí nad Labem, České mládeže 8, 40096 Ústí nad Labem, Czech Republic.

Tel.: +420.475.283.614.

E-mail: Jaromir.Hajer@ujep.cz

Key words: Spiders; Haplogynae; spinnerets; spigots; silk.

Acknowledgements: the authors gratefully acknowledge suggestions made by the reviewers and the editor, which helped to improve the manuscript. This study was supported by the Grant Agency of J. E. Purkinje University in Ústí nad Labem, Czech Republic.

Received for publication: 14 April 2016.

Revision received: 15 November 2016.

Accepted for publication: 16 November 2016.

@C Copyright S. Karschová and J. Hajer, 2016

Licensee PAGEPress, Italy

Journal of Entomological and Acarological Research 2016; $48: 5934$

doi:10.4081/jear.2016.5934

This article is distributed under the terms of the Creative Commons Attribution Noncommercial License (by-nc 4.0) which permits any noncommercial use, distribution, and reproduction in any medium, provided the original author(s) and source are credited.

\section{Introduction}

Spinning activity is a prominent feature of spiders, although there are also other groups of invertebrates capable of producing silk (Sutherland et al., 2010). The silk-spinning apparatus of spiders consists of spinnerets and silk-spinning glands. Spinning glands, located in the opisthosoma, are emptied through sets of outlets, known as spigots or (less frequently) nozzles. Silk-producing glands originate from ectodermal invaginations on the embryonic spinneret limb buds (Hilbrant \& Damen, 2015). The spinning gland cells are capable of producing different types of silk secretions. Spiders have a number of different appendage types with radically different adult morphologies (Pechmann et al., 2010). Spinnerets are highly modified opisthosomal appendages (Kautzch, 1910; Yoshikura, 1955) that arise embryologically from the same longitudinal series of limb buds (Dawydoff, 1949) which give rise to the prosomal appendages, i.e. chelicerae, pedipalps and legs (Dawydoff, 1949; Whitehead \& Rempel, 1959).

Evolution of the order Araneae most likely occurred along three major evolutionary lines, currently represented by the infraorders Mesothelae, Mygalomorphae, and Araneomorphae (Coddington \& Levi, 1991). The silk-producing organs are the most remarkable organs exhibiting differences in their structures among the infraorders. The oldest known silk-producing spigots date back to the Middle Devonian of Gilboa, New York, USA (Shear et al., 1989) and their spinneret was very much like the posterior median spinnerets of the spider infraorder Mesothelae (Selden et al., 2008).

The Mesothelae are the most archetypal of recent spiders known (Haupt, 2003). The most thoroughly described genera are Liphistius Schiödte, 1849, from South and South-East Asia, and Heptathela Kishida, 1923, which includes 33 species from Japan, Vietnam and China (World Spider Catalog, 2016). Liphistius has four pairs of spinnerets: two pairs of multisegmental lateral and two pairs of monosegmental median. In Heptathela kimurai the posterior and the median pairs of spinnerets merge to form a single unpaired spinneret without spinning capabilities (Haupt \& Kovoor, 1993). Except for the Mesothelae, four pairs of spinnerets are never present, since an anterior median pair has not developed.

Evolution has led to great diversity in the spinning apparatus of present day spiders seen from structural, functional, physical and chemical aspects of the silk secreted and spun by members of the various families (Kovoor, 1987).

The Araneomorphae, known as true spiders and with the largest number of species, possess three pairs of spinnerets, namely the anterior lateral (ALS), posterior median (PMS), and posterior lateral spinnerets (PLS). In some Araneomorphae, the spinning apparatus includes a functional homolog of anterior median spinnerets called the 'cribellum'. In other true spiders, including the Segestriidae family, the alternative homolog of anterior lateral spinnerets is a non-functional colulus (Foelix, 2011). 
Segestriidae belongs to the haplogyne Dysderoidea superfamily, which comprises also the Dysderidae, Oonopidae and Orsolobidae families (Coddington \& Levi, 1991). Spider families referred to as the Haplogynae possess a developed so called haplogyne type of genitalia, with females presenting fused copulation and fertilization ducts and male palps presenting reduction and fusion of the sclerites of the bulb (Coddington, 2005). The mutual relationship of all four above mentioned families has been previously confirmed in phylogenetic studies (Coddington, 2005; Michalik \& Ramírez, 2014). The silk of all dysderoids is produced by glands called Glandulae ampullaceae, Glandulae piriformes and Glandulae aciniformes (Glatz, 1972; Hajer et al., 2013; Murphy \& Roberts, 2015). The spigots which serve to emit the ampullate gland silk in Dysderidae, Oonopidae and Orsolobidae are located individually on the spinning fields of anterior lateral spinnerets. In reference to their size, these glands are called major ampullate glands and the silk which is produced therein is called major ampullate or also dragline silk (Kovoor, 1987). The spinning fields of ALSs also contain the spigots of piriform glands.

Spinnerets of Segestria senoculata (Linnaeus, 1758) were first described by Apstein (1889), which found out that the spinnerets of this species are equipped with the spigots of ampullate, piriform and aciniform glands. The same glands were described in this species by Millot (1931). The spinning apparatus of Segestriidae, including the histochemical characteristics of their spinning glands, was described by Glatz (1972). Piriform spigots, with low, flat basal parts, were described by Bílek (1992). Until now there are no works focusing on the SEM study of segestriid silks. The Segestriidae family is also remarkable by the fact that has developed one other pair of ampullate glands which are not found in other dysderoids (Glatz, 1972). These glands, which supply the posterior median spinnerets, are currently known as the minor ampullate glands (Platnick et al., 1991; Griswold et al., 2005; Murphy \& Roberts, 2015). However Glatz (1972), despite mentioning variability in shape among the ampullate glands, considered both the major and minor ampullate glands to fall under a single common category of spinning glands. Aciniform spigots are located on the posterior median and posterior lateral spinnerets (Murphy \& Roberts, 2015). Based on his detailed histological study of the silk-producing glands, Glatz (1972) called these Glandulae pseudaciniformes and the same name was used by the authors of this study (see Discussion).

The segestriids are nocturnal sedentary hunters that live in a variety of habitats. They may be abundant in areas of favorable habitats, such as rock walls, rock talus and under loose tree bark (Ubick, 2005), where they build tubular retreats with trip-lines radiating from the opening. These signal lines extending away from the tube are used by the spiders to detect preys (Bradley, 2013). Similar retreats are also constructed by some other spiders belonging to the Dysderoidea superfamily (Ubick, 2005).

The aims of the research, the results of which are presented in this paper, were: i) to study the morphology of the spinnerets, in particular their spigots through which the silk is emitted onto a surface; ii) to describe, by means of scanning electron microscopy (SEM), the microstructure of the silk fibers used by Segestria senoculata to build its tube-like shelters; and iii) to describe the spinning behavior and the movements of the spinnerets when the silk fibers are emitted.

Our hope is that data presented in this paper may contribute to a better understanding of the organization of constituents in the silk-producing system of the superfamily Dysderoidea.

\section{Materials and methods}

\section{Materials and keeping spiders in laboratory conditions}

Spiders of European species (World Spider Catalog, 2016) S. senocula- $t a$ are, similarly to other species of the Segestriidae, usually found in silk tubular retreats with signal threads radiating from their entrances (Figure 1A-C). In the Czech Republic, these spiders are abundant under tree barks and under stones found in forests, under stones on scree slopes and also inside rock fissures (Buchar \& RůŽička, 2002). The specimens studied for this contribution ( 16 females, 11 males and 6 nymphs) were found and collected in the vicinity of the town of Děčin (Northern Bohemia, Czech Republic, 50.8122325N, 14.3256342E). The specimens were kept in tubular vials (100 mm long and $15 \mathrm{~mm}$ in diameter), which were closed using balls of cotton wool, and also in cubic glass containers measuring $7 \times 7 \times 7 \mathrm{~cm}$; small pieces of the moistened moss Hypnum cupressiforme Hedw. were placed inside these breeding boxes, The body length of adult specimens of both sexes measured up to 8-9 mm, the body length of nymphs collected in parental tubes was $4 \mathrm{~mm}$. All of the spiders were fed once a week with suitably-sized insects. The observations were carried out between October 2013 and February 2015. Voucher specimens were deposited at the Department of Biology, Faculty of Science, J.E. Purkinje University in Ústí nad Labem, Czech Republic.

\section{Microscopic and imaging equipment}

Live spiders and their behavior during spinning activity were observed with a stereo microscope NOVEX, which was equipped with an INFINITY LITE Digital Camera. For a detailed study of the spinning apparatus, spinnerets were observed by a light microscope LEICA DMLB, following prior tissue digestion with $20 \% \mathrm{KOH}$ solution at $\sim 100^{\circ} \mathrm{C}$ in a glass test-tube. Dissection for further spinneret observation was carried out on $80 \%$ ethanol-fixed specimens. The spinnerets were mounted in Liquido de Swan (Hrbáček, 1969), observed and drawn (Figures 2B and 3B,D,F) using a LEICA DMLB light microscope equipped with a drawing apparatus. For scanning electron microscopy studies, the spiders were dehydrated in a graded series of ethanol and critical point dried with carbon dioxide. The morphology of the spinning apparatus and the ultrastructure of silk fibers were studied, after gold coating, under a TESCAN Scanning Electron Microscope (Figures $2 \mathrm{~A}$ and $3 \mathrm{~A}, \mathrm{C}, \mathrm{E}$ ) and UHR-SEM Zeiss Ultra Plus (Figures 4 and 5), which operated at low acceleration voltage of $5 \mathrm{kV}$.

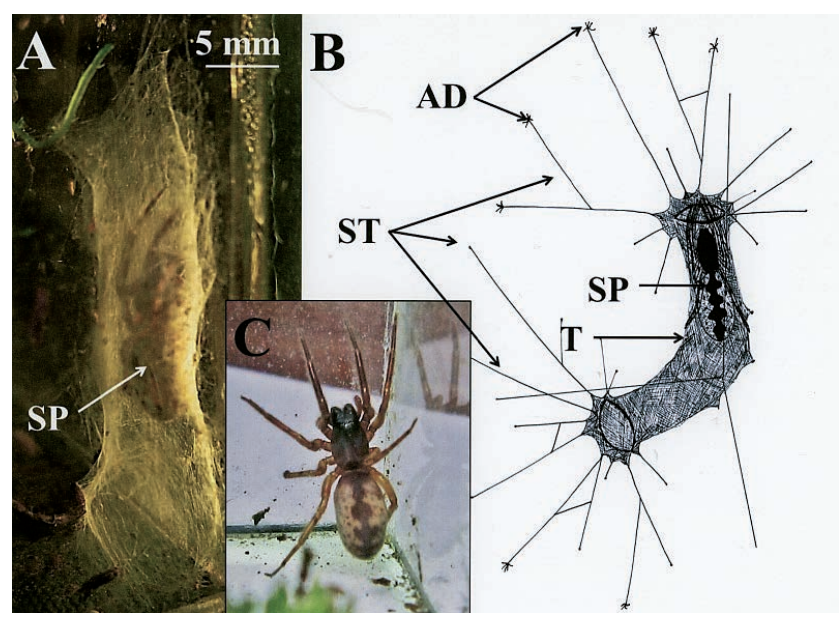

Figure 1. A) Adult female Segestria senoculata and her tube-like retreat, constructed inside a glass container. B) Line drawing of the retreat with signal threads. The silk is attached to substratum via attachment discs. C) Adult female with median dark stripe broken into chevrons on her dorsal opisthosoma and with the first two legs oriented forward. AD, attachment disc; SP, spider, ST, signal threads; T, silken tube. 


\section{Method of obtaining samples of silk for scanning electron microscopy}

For the mechanical harvesting of intact silk samples, suitable for investigation of their micro- and ultrastructure, selected spiders were kept for a certain period of time inside thin-walled transparent plastic containers measuring $7 \times 7 \times 12 \mathrm{~cm}$. When the spiders finished building a complete web, the plastic walls of the container were cut into small pieces, and the silk attached to them was studied using SEM. Some spiders were kept individually in cubic containers made of six pieces of microscope cover glass $(22 \times 22 \mathrm{~mm})$ which were glued together. The spinning of retreats was observed with a stereo microscope. The observation could be interrupted at any point to remove the cover glass container and collect silk from retreats under construction.

\section{Results}

\section{Morphology of the spinning apparatus and spinneret spigots}

The spinning apparatus consists of three pairs of spinnerets in which four kinds of spinning glands supply four types of spigots (Figure 2A,B).

Anterior lateral spinnerets (ALSs) consist of three segments (Figure $3 \mathrm{~A}-\mathrm{B})$, the spinning field of the apical segment of each of them is equipped with 12-14 piriform spigots and one major ampullate spigot, which is placed (Figures 2B and 3A-B) on the inner margin of the spinning field. Both types of the spigots are easily distinguished from each other due to both their size and their position on the spinning fields of ALSs. When compared with the piriform spigots, the terminal part of the ampullate spigot (i.e., the shaft) is longer and thicker, and its basal part consists of a larger socket. The number of anterior lateral spinneret spigots did not vary among adult females and adult males observed. ALSs of the six studied juveniles were each equipped with one major ampullate spigot and two piriform glands spigots.

Posterior median spinnerets (PMSs) are the smallest of the three pairs of spinnerets (Figures 2A-B and 3C-D), have a cylindrical shape and consist of only one segment. In either adult males or adult females, each spinneret is equipped with one minor ampullate spigot (mA) and two pseudaciniform spigots (PA). PMSs of juveniles carry one mA and
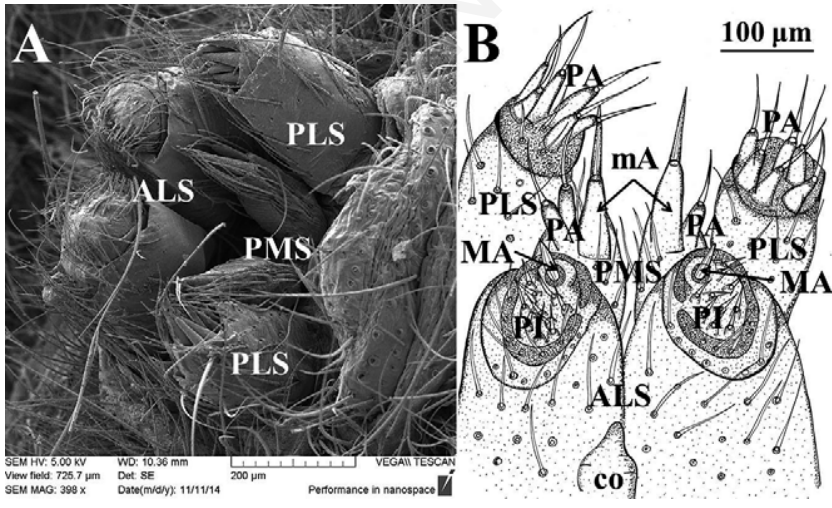

Figure 2. Scanning electron micrograph (A) and line drawing (B) of the spinnerets found on an adult female. ALS, anterior lateral spinnerets; CO, colulus; MA, major ampullate spigots; $\mathrm{mA}$, minor ampullate spigots; PA, pseudaciniform spigots; PI, piriform spigots; PLS, posterior lateral spinnerets; PMS, posterior median spinnerets. one PA spigots. Although the minor ampullate spigots are larger in size than the pseudaciniform spigots, both of the types are very similar in appearance due to their shared shape and surface ultrastructure showing longitudinally grooved sockets and shafts.

Posterior lateral spinnerets (PLSs) are made up of two segments (Figures 2A-B and 3E-F). Both female and male specimens show 6-7 pseudaciniform spigots located on the surface of the terminal part of the apical segment. There are no morphological differences between the spigots (Figures 3C-F and 4) of posterior lateral and posterior median spinnerets. PLSs of juveniles each carry two spigots of pseudaciniform glands. The spinning apparatus of juveniles is thus complete and is capable (similarly to adult stages) of producing draglines, signal threads, attachment discs and the silk of the retreat.

During the ontogenesis, the number of major and minor ampullate glands (i.e. those glands that provide material for making draglines and signal threads) remains unchanged, while the initially small number of piriform and pseudaciniform glands increases. Increasing the number

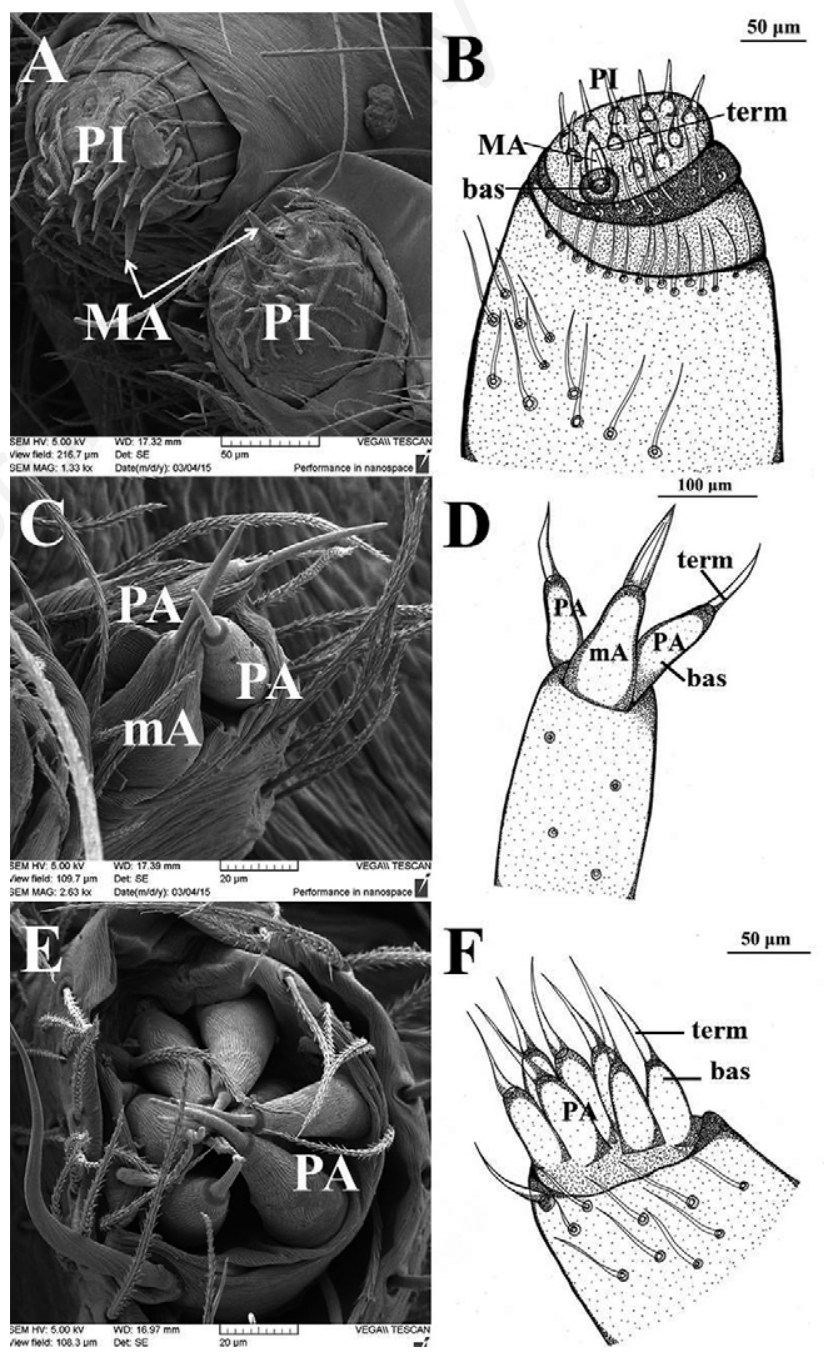

Figure 3. Scanning electron micrograph (A, C, E) and line drawing $(B, D, F)$ of the spinning fields and arrangement of spigots of the silk-spinning apparatus of an adult female. A and B) Anterior lateral spinnerets. C and D) Posterior median spinnerets. E and F) Posterior lateral spinnerets. bas, basal part of spigot (socket); MA, major ampullate spigots; $\mathrm{mA}$, minor ampullate spigots; PA, pseudaciniform spigots; PI, piriform spigots; term, terminal part of spigot (shaft). 
of these glands, after the juveniles leave their maternal tube, is associated with the gradual increase of the spider body after each ecdysis as well with the growing need to produce the silk material for construction the tubular retreat of larger dimensions.

The cuticle surrounding the spinning fields of all three pairs of spinnerets is covered with plumose hairs (setae) (Figures 4 and 5), which resemble tactile hairs in appearance (Foelix, 2011) and in contrast to spigots (which are generally considered as metamorphosed setae), emerge from less-developed sockets.

\section{Colulus}

Colulus appears to be an unpaired protuberance whose distal part is narrower than the basal part (Figure 2B). Plumose setae cover completely the surface of colulus (Figure 5) and can be observed also on its close surfaces of opisthosoma.

\section{Silks}

Segestriids use their silks in order to create retreats (Figures 1A$\mathrm{B}, 7 \mathrm{~A}$ ), draglines (Figure 6), signal threads and attachment discs (Figure 7B-D).

Draglines, i.e. threads which the spiders drag behind them when moving (and on which they remain suspended during free fall) are produced by anterior lateral spinnerets together with attachment discs. The liquid silk used for draglines is secreted by a pair of major ampullate glands. The movements of anterior lateral spinnerets during the spinning activity are synchronized and the major ampullate spigots located on the inner side of both anterior lateral spinnerets touch each other as they emit draglines. Therefore, each individual dragline is made up of a pair of parallelly oriented fibrils, with each individual fibril being emitted by a single major ampullate spigot. Solidified dragline fibers are connected to the substratum by means of attachment discs, which are made of the secretion produced by the piriform glands. The silk produced by piriform glands is applied onto the substratum by rotating movements of the two ALSs and by rubbing the spinning fields and spigots against the substratum. The fibrils emerging from each piriform spigot remain separated (Figure 7B-C). Draglines, comprising a pair of parallel fibrils emitted through the major ampullate spigots, are (together with minor ampullate silk) part of the signal threads.

The activity of the pair of minor ampullate glands leads to the secretion of silk used for the making of signal threads. During the spinning activity leading to the formation of parallelly oriented fibrils, the spigots emitting the gradually solidifying secretion upon the surface of the posterior median spinnerets are mutually touching, similar to the spigots of major ampullate glands. Pseudaciniform glands, which supply the posterior median and posterior lateral spinnerets (Figure 3A-F), provide the material for those retreats in which the spiders find shelter during ecdysis and in which the females lay (and later guard) their eggs.

\section{Building a retreat}

As mentioned in the previous text, the web of $S$. senoculata is comprised of two constitutional parts: i) the densely woven silken tube with circular opening on both ends; and ii) the system of signal threads which is connected to it. Before spiders begin to weave this intricate web, the signal threads are the first to be made.

The process of signal threads formation begins with the spider creating a spot of piriform silk at a certain location (which is some distance further from where it will later build the tube itself) and then dragging these signal threads towards the placement of the future entrance orifice of the tube. Here, the threads are again connected to the ground with the use of another attachment disc. This spot of piriform silk represents a centre, towards which all the proximal ends of signal threads come together. The above-described procedure is repeated several times, leading to the formation of several signal threads

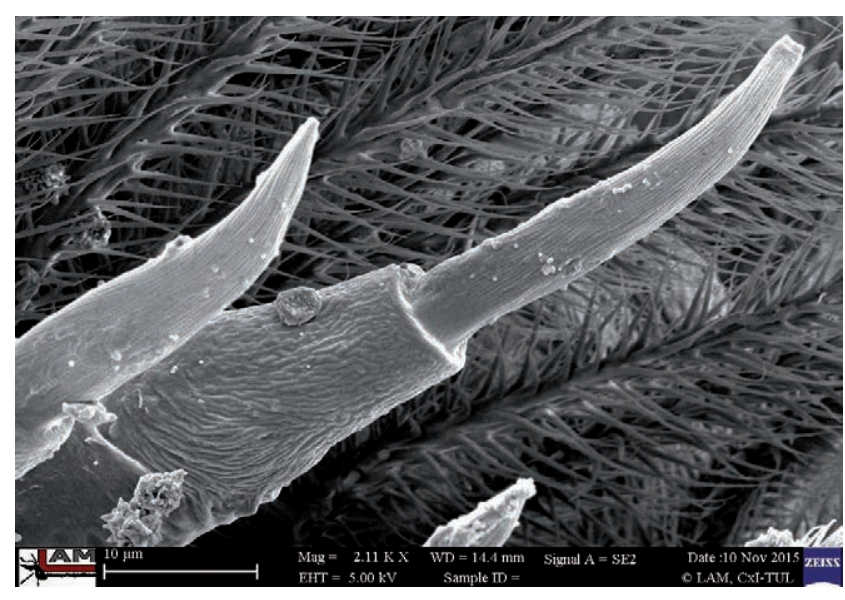

Figure 4. Detail of pseudaciniform spigots.

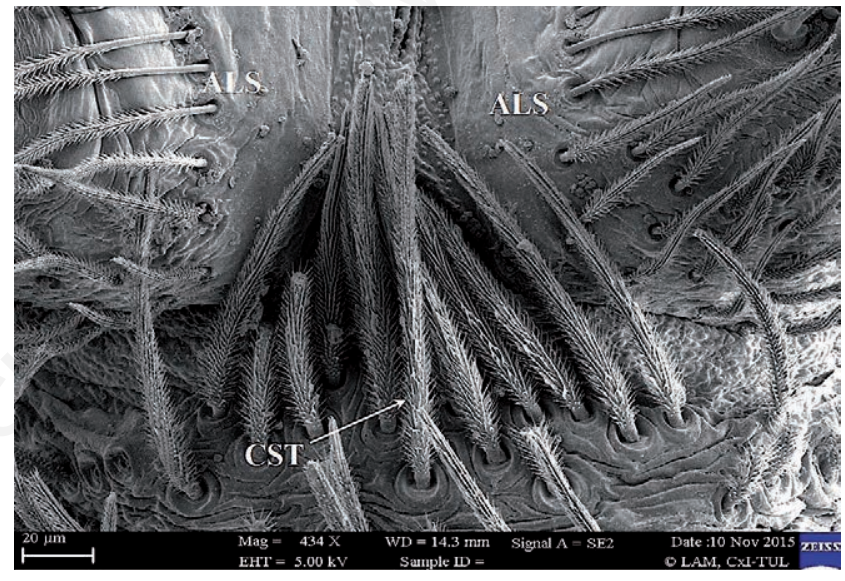

Figure 5. Scanning electron micrograph of hairy colulus of an adult male. Tubercle (Figure 2B) is completely covered by plumose setae. ALS, anterior lateral spinnerets; CST, colular setae.

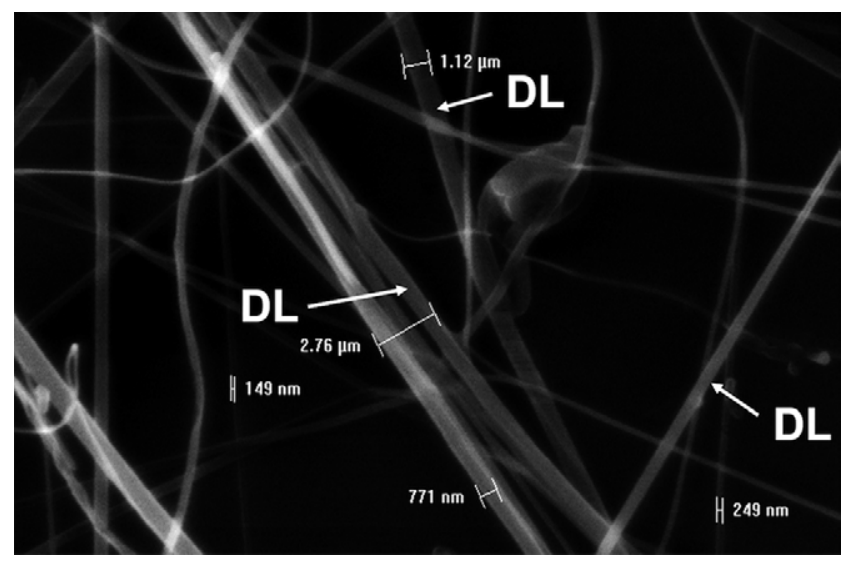

Figure 6. Scanning electron micrograph of the dragline (DL) stretched on the microscope cover glass by an adult female immediately after her insertion into the breeding vessel. The bars mean the diameter of the thread. The thin threads are produced probably by the minor ampullate glands. 
located at both ends of the future tube. An accumulation of silk can be observed at the spot where the minor ampullate silk is connected to the attachment discs. This process probably ensures an even stronger connection between the signal threads and the substratum (Figure 7D).

Any movement the spider makes while building the web is also accompanied by the dragging of one more additional line behind it, an already mentioned thread called a dragline. That means that dragline silk is emitted during the formation of signal threads, whose base material and fundamental axis is made up of silk produced by the minor ampullate glands (mAP). However, during the motions exhibited by the spider while building a web (and later on while attacking for its prey) these mAP threads are parallelly joined by threads created by the activity of major ampullate glands (MAP). In older webs that have been in use for several weeks, the draglines create a whole network of threads, which are also stretched in a crosswise fashion between the signal threads and the nearest vicinity of the tube.

When the spider is finished with creating a system of signal threads, it uses the motions of its opisthosoma and spinnerets in order to begin weaving the base of the tube.

Immediately following the creation of orifices on both ends of the tube, these ends are connected with signal threads using the same silk, which was used to formation the tube. This silk is supplied by pseudoaciniform glands. The once sparsely weaved, translucent wall of the future retreat becomes thicker and stronger as new layers are added on. In the construction of the walls of the tube, the emitted strands of hardening pseudaciniform silk are added to already existing fibers by smearing silk secretion onto already existing fibers. When weaving the retreat tube, the posterior median and posterior lateral
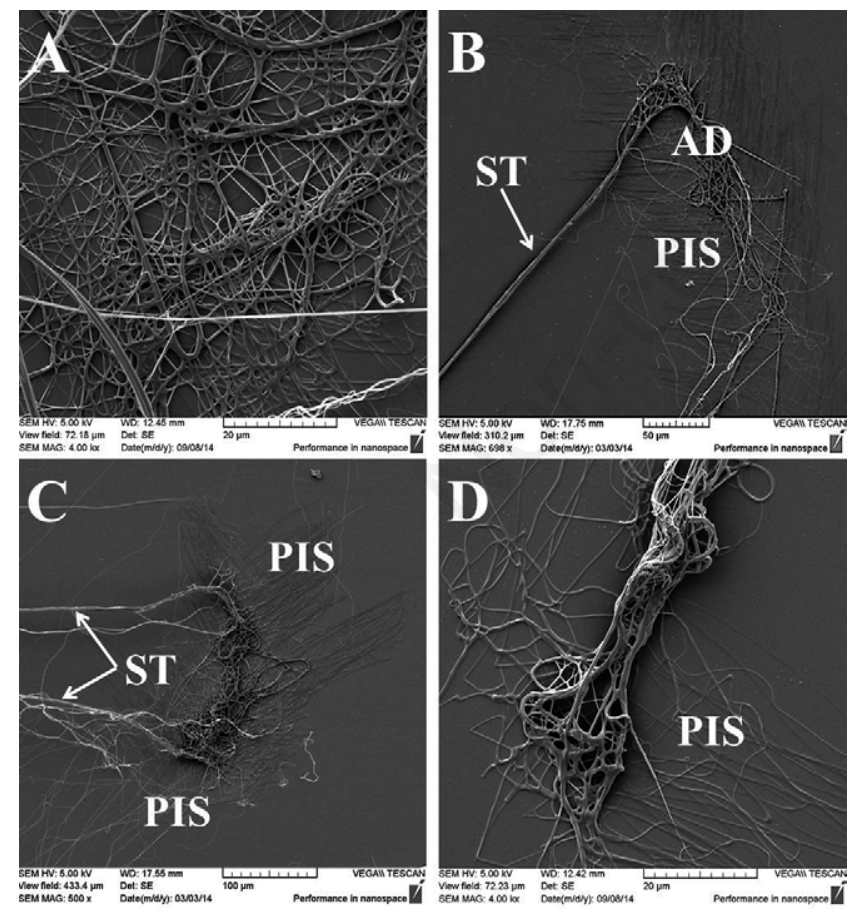

Figure 7. Scanning electron micrographs of different types of fibers produced by an adult female inside the breeding vessel. A) Detail of the microstructure of the retreat's silk. B) Signal thread and its adjunction to the substratum by a silk attachment disc. C) Two signal threads with interconnected attachment discs. D) Accumulated minor ampullate silk of one of the signal threads located in the site of intersection with piriform gland silk. $\mathrm{AD}$, attachment disc; PIS, piriform gland silk; ST, signal thread. spinnerets either touch each other (i.e. their spinning fields carrying spigots are close to each other) or, alternatively, the movements of spinnerets of the same pair are asynchronous and their spinning fields point in different directions while emitting the silk. Thus, a dense mesh-like tangle of fiber bundles of uneven thickness is created (Figure 7A).

When the retreat tube is finished, draglines are stretched between its walls and the objects nearest to it. These fibers help in maintaining the shape of the tube and also keep it passable at all times.

\section{Discussion}

\section{The use of silk}

Spiders can be classified as either generalists or specialists according to the structure and composition of their spinning apparatus and correlatively to the use of the silk produced (Kovoor, 1987). The generalist spiders produce one to three kinds of fibers, which are indifferently used for the construction of their retreats (or burrows) as well as egg sacs or sperm webs (Kovoor, 1987). Based on the above-mentioned criteria, dysderoids fall under the category of generalists, with the exception of segestriids for which the current research, focused on their spinning apparatus, confirmed the presence of four different types of spigots and spinning glands. Apart from the major ampullate glands/spigots, segestriids also possess developed minor ampullate glands and could therefore fall under the specialists category, which encompasses spider families with four to nine different types of spinning glands.

Dysderoids construct tubular silk retreats in which nocturnal spiders rest during the day (Jocqué \& Dippenaar-Schoeman, 2006). The same silken tube can also be used by the spiders as a temporary shelter or for depositing eggs, which are loosely bound with silk and guarded by the female. However, only segestriids, contrary to the members of the other three dysderoid families, create signal lines-equipped webbing at the entrances.

In Segestriidae, the signal lines (also called trip wires) are monitored by the spider's anteriorly directed legs (i.e., the first three pairs), and indicate the position and size of approaching prey. This behavior allows the spider to capture rapidly the prey, which is then pulled into the retreat for feeding. The ability to spin signal threads and, thus, to use their silk for preying is associated in Segestriidae with the presence of minor ampullate glands, which are not developed in the other families of the Dysderoidea superfamily (Glatz, 1972; Kovoor, 1987; Arnedo et al., 2000; Hajer et al., 2013; Hajer et al., 2014a, 2014b).

\section{Silk glands}

Apstein (1889) studied the anatomy of the spinning apparatus in number of families (including Segestriidae) of araneomorphs. He classified the silk glands, accordingly to their shape and which spinnerets they supply, into categories that are still valid, with a slight improvement of modifications with respect to recent studies. The silk-producing organ often undergoes adaptive variations but some basic familial characteristic usually remain unchanged. The major trend in the evolution of the spinning apparatus in araneomorphs seems to be a functional specialization of each pair of spinnerets and afferent glands, involving precise modifications of the shape of the spinnerets, the number and morphology of spigots and the anatomical and histochemical characteristics (Kovoor, 1987; Townley et al., 1991).

Glatz $(1972,1973)$ performed a very thorough histological and histochemical analysis of silk glands of several families of haplogyne araneomorphs and mygalomorphs and discovered that $S$. senoculata is equipped with four types of glands/spigots: Glandulae ampullaceae major (MA), Glandulae piriformes (PI), Glandulae ampullaceae minor 
(mA) and Glandulae pseudaciniformes (PA). These glands supply the anterior lateral spinnerets (MA + PI), the posterior median spinnerets $(\mathrm{mA}+\mathrm{PA})$ and the posterior lateral spinnerets $(\mathrm{PA})$. On the contrary to the majority of araneomorph spiders, the females of $S$. senoculata (as well as other Dysderoidea) do not have developed Glandulae tubuliformes, which are needed for the formation of egg sacs (Glatz, 1972).

Our SEM study of spigots confirmed the presence of four morphologically different types of spigots. Practically, the same microstructure of spinneret and spigot distribution was reported in adult males and females of Ariadna boesenbergi Eugen von Keyserling, 1877 (Segestriidae) by Griswold et al. (2013).

Minor ampullate silk is typically thinner and weaker than major ampullate silk while at the same time being more extensible (Blackledge, 2013). Minor ampullate threads also sometimes supplement draglines and web elements spun from major ampullate glands/spigots (Blackledge, 2013; Garb, 2013). Minor ampullate silk is so named because the structure of its gland resembles a smaller version of the major ampullate silk. Orb web spiders (Araneidae) possess a single pair of minor ampullate glands on their posterior median spinnerets (Peters \& Kovoor, 1991; Townley et al., 1991) that produce a type of thread, which is sometimes added to major ampullate draglines (Coddington, 1989). These threads are also added to major ampullate draglines by $S$. senoculata spiders when making their signal threads. The main differences between major and minor ampullate glands are given chiefly by the protein composition of the secret they produce. For example, for the orb web spider Nephila clavipes (Linnaeus, 1767) (Araneidae) a total of 125 proteins were identified in the major ampullate, 68 in the minor ampullate and 23 in aciniform glands (Pinto et al., 2016). It would undoubtedly be interesting to find out to which extent do the protein composition of the above mentioned silk-producing glands of Araneidae (in which the webs and wrapping behaviour play an active role in prey capture) and Segestriidae match.

\section{Glandulae aciniformes}

In most families these glands are composed of two categories of tall secretory cells, each occupying the distal or proximal glandular region, which may be more or less extended (Richter, 1970; Kovoor, 1987; Peters \& Kovoor, 1991). Glandulae aciniformes, together with Glandulae piriformes represent two different categories of spinning glands, which conserve the primitive acinous morphology and small size (Kovoor, 1987). Aciniform silk is the toughest spider silk and is composed of the protein aciniform spidroin 1 (AcSP1) (Tremblay et al., 2016). The name Glandulae pseudaciniformes was first applied by Glatz (1972), who used it for Dysderidae and Segestriidae, in order to distinguish their aciniform glands from the aciniform glands of spiders of other families. Up until then, no one else used the term in order to describe the spinning glands of these families. In current arachnology, it is perfectly common to presume the presence of Glandulae aciniformes based only on spigots, without any further knowledge of the histology and histochemistry of the glands connected to them. It is precisely the shape of these spigots which is the reason for their widely accepted name - Glandulae aciniformes. In the araneomorphs, this term stands for small-sized glands with spigots, which in Segestriidae are placed (similarly to most, if not all of the families of the Araneomorphae infraorder) on the posterior median and posterior lateral spinnerets (Coddington, 1989). The structural and histochemical characteristics of aciniform glands vary extensively from one systematic group to another. Aciniform silk is likely to be similar to the earliest types of spider silks, such as the relatively undifferentiated sheets of threads produced by spiders of the infraorder Mygalomorphae (Glatz, 1972; Shear et al., 1989; Blackledge, 2013). Orb web spiders (Araneidae) and wolf spiders (Lyoosidae) show varying numbers of aciniform spigots on their posterior median and posterior lateral spinnerets (Townley et al., 1991; Townley \& Tillinghast, 2009; Dolejš et al., 2014). The silk produced by these structures is used prima- rily for prey wrapping and egg sac construction. It is also used by some orb web spiders in order to produce stabilimenta, also known as 'web decorations' (Walter et al., 2008; Blackledge, 2013). The function and possibly the properties of aciniform silk of orb weavers and segestriides are not easily comparable, because the spiders of the Segestriidae family do not display any wrapping behaviour when manipulating their prey, their eggs are not laid into egg sacs and nor are their webs equipped with stabilimenta.

The variability in the number of aciniform glands and spigots can be observed also in adult of $S$. senoculata. When discussing on the number of spigots these glands possess, both Apstein (1889) and Millot (1931) report the presence of eight spigots -2 PMS +6 PLS (pertaining to a half of the spinning apparatus). Glatz (1972) discovered the presence of eleven spigots (3 PMS +8 PLS). Authors of this paper report nine discovered pseudoaciniform spigots (2 PMS + 7 PLS) and as such these findings are almost identical to those reported by both Apstein (1889) and Millot (1931).

\section{Morphology of spinning fields}

Detailed SEM study of $S$. senoculata spinnerets did not confirm the presence of so-called tartipores on the spinning fields of this species. The tartipores are cuticular scars, morphologically singular or multiple, which are formed following ecdysis from a collared opening that is shaped in the exoskeleton during proecdysis. This opening serves to accommodate a silk gland duct, allowing it to remain attached to a spigot located on the old exoskeleton during proecdysis (Dolejš et al. 2014). Tartipores are found on the spinning fields of many entelegyne specialists with a much larger spinning glands diversity than the one found in Segestriidae, starting with the second instar. The function of these structures was described in depth by Townley \& Tillinghast $(2003,2009)$ and Dolejš et al. (2014). Segestriidae do not possess developed secondary (those that are tartipore-accommodated) ampullate glands (and their spigots) and none of the identified silk glands categories are tartiporeaccommodated (Garrison et al., 2016). The evolution of tartipore-accommodated glands corresponds with the way spiders secure themselves when undergoing the process of moulting (Dolejš et al., 2014). Absence of secondary ampullate glands (both major and minor) represents probably the most important characteristic of silk-producing organs of Dysderoidea, a clade or superfamily of araneomorph spiders.

\section{References}

APSTEIN C., 1889 - Bau und Funktion der Spinndrüsen der Araneida. Arch. Naturgesch. 55: 29-74.

ARNEDO M.A., OROMÍ P., RIBERA C., 2000 - Systematics of the genus Dysdera (Araneae, Dysderidae) in the Eastern Canaries. - J. Arachnol. 28: 261-292.

BÍLEK P., 1992 - Cuticular spinning structures reveal evolutionary relationships in araneomorph spiders. - Sb. V d. Pr. Lék. Fak. Univerzity Karlovy v Hradci Králové, 35: 353-370.

BLACKLEDGE T.A., 2013 - Spider silk: molecular structure and function in webs. In: NENTWIG W. (Ed.), Spider ecophysiology. - SpringerVerlag, Berlin-Heidelberg: 267-282.

BRADLEY R.A., 2013 - Common Spiders of North America. - University of California Press, Berkeley: $271 \mathrm{pp}$.

BUCHAR J., RŮŽIČKA V., 2002 - Catalogue of Spiders of the Czech Republic. - Peres, Praha: 351 pp.

CODDINGTON J.A., 1989 - Spinneret silk spigot morphology: evidence for the monophyly of orbweaving spiders, Cyrtophorinae (Araneae), and the group Theridiidae plus Nesticidae. - J. Arachnol. 17: 71-95.

CODDINGTON J.A., LEVI H.W., 1991 - Systematics and evolution of spiders (Araneae). - Ann. Rev. Ecol. Syst. 22: 565-592. 
CODDINGTON J. A., 2005 - Phylogeny and classification of spiders. In: UBICK D., PAQUIN P., CUSHING P.E., ROTH V. (Eds.), Spiders of North America: an identification manual. - American Arachnological Society, College Park, MD: 18-24.

DAWYDOFF C., 1949 - Développement embryonnaire des Arachnides. In: GRASS P.P. (Ed.), Traité de Zoologie, VI. - Masson, Paris: 320-395.

DOLEJŠ P., BUCHAR J., KUBCOVÁ L., SMRŽ J., 2014 - Developmental changes in the spinning apparatus over the life cycle of wolf spiders (Aranee: Lycosidae). - Invertebr. Biol. 133: 281-297.

FOELIX R., 2011 - Biology of spiders, $3^{\text {nd }}$ ed. - Oxford University Press, New York: 419 pp.

GARB J., 2013 - Spider silk: An ancient biomaterial for the 21st century. In. D. PENNEY (Ed.), Spider research in the 21st century: trends and perspectives. - Siri Scientific Press, Manchester: 252-281.

GARRISON N.L., RODRIGUEZ J., AGNARSSON I., CODDINGTON J.A., GRISWOLD C.E., HAMILTON C.A., HEDIN M., KOCOT K.M., LEDFORD J.M., BOND J.E., 2016 - Spider phylogenomics: untangling the Spider Tree of Life. PeerJ. 4: e1719.

GLATZ L., 1972 - Der Spinnapparat haplogyner Spinnen (Arachnida, Araneae). - Z. Morphol. Tiere. 72: 1-26.

GLATZ L., 1973 - Der Spinnapparat der Orthognatha (Arachnida, Araneae). - Z. Morphol. Tiere. 75: 1-50.

GRISWOLD C.E., RAMÍRÉZ M.J., CODDINGTON J.A., PLATNICK N.I., 2005 - Atlas of Phylogenetic Data for Entelegyne spiders (Araneae: Araneomorphae: Entelegyne) with Comments on their Phylogeny. Proc. Calif. Acad. Sci. 56: 1-324.

GRISWOLD C., 2013 - Atlas of Entelegynae. - California academy of sciences. Available from: http://researcharchive.calacademy.org/ research/entomology/EntomologyResources/Arachnida/Atlas of Entelegynae.htm

HAJER J., MALÝ J., ŘEHÁKOVÁ D., 2013 - Silk Fibers and Silk Producing Organs of Harpactea rubicunda (C.L. Koch 1838) (Araneae, Dysderidae). - Micros. Res. Tech. 76: 28-35.

HAJER J., CZERNEKOVÁ M., ŘEHÁKOVÁ D., 2014a - Silk-producing organs of the troglobitic spider species Rhode aspinifera (Nicolic, 1963) (Araneae: Dysderidae). - North-West. J. Zool. 10: 133-137.

HAJER J., CZERNEKOVÁ M., ŘEHÁKOVÁ D., 2014b - Silk spinning apparatus and silk microstructure of Silhouettella loricatula (Araneae, Araneomorphae, Oonopidae). - Trends Entomol. 10: 29-38.

HAUPT J., KOVOOR J., 1993 - Silk gland system and silk production in Mesothelae. - Ann. Sci. Nat. Zool. Biol. Anim. 14: 35-48.

HAUPT J., 2003 - The Mesothelae - a monograph of an exceptional group of spiders (Araneae: Mesothelae). - Zoologica 154: 1-102.

HILBRANT M., DAMEN W.G.M., 2015 - The embryonic origin of the ampullate silk glands of the spider Cupiennius salei. - Arthropod Struct. Dev. 44: 280-288.

HRBÁČEK J., 1969 - Zhotovování mikroskopických preparát a jejich uspo ádání. In: K. NOVÁK (Eds.), Metody sběru a preparace hmyzu. Academia, Praha: 77-83.

JOCQUÉ R., DIPPENAAR - SCHOEMAN A.S., 2006 - Spider families of the world. - Royal Museum for Central Africa, Tervueren: 336 pp.

KAUTZCH G., 1910 - Über die Entwicklung von Agelena labyrinthica Clerk. - Zool. Jahrb. Abt. Anat. Ontog.Tiere. 28: 30-36.

KOVOOR J., 1987 - Comparative structure and histo-chemistry of silkproducing organs in arachnids. In: NENTWIG W. (Ed.), Ecophysiology of Spiders. - Springer-Verlag, Berlin: 160-186.

MICHALIK P., RAMÍREZ M.J., 2014 - Evolutionary morphology of the male reproductive system, spermatozoa and seminal fluid of spiders (Araneae, Arachnida) - Current knowledge and future directuins. - Arthropod Struct. Dev. 43: 291-322.
MILLOT J., 1931 - Les glandes séricigènes des Dysdérides. - Arch. Zool. Exp. Gen. 71: 38-45.

MURPHY J.A., ROBERTS M.J., 2015 - Spider families of the world and their spinnerets. - British Arachnological Society, York: PART I (Text): 189 pp. Part II (Plates): 553 pp.

PECHMANN M., KHADJEH S., SPRENGER F., PRPIC N.M., 2010 Patterning mechanisms and morphological diversity of spider appendages and their importance for spider evolution. - Arthropod Struct. Dev. 39: 453-467.

PETERS H.M., KOVOOR J., 1991 - The silk-producing system of Linyphia triangularis (Araneae, Linyphiidae) and some comparisons with Araneidae. Structure, histochemistry and function. Zoomorph. 111: 1-17.

PINTO J.R.A.S., GARCIA A.M C., ESTEVES F.G., SALLES H.C., LUBEC G., PALMA M.S., 2016 - Silkomics: insight into the spinning process of spiders. - J. Proteome Res. 15: 1179-1193.

PLATNICK N.I., CODDINGTON J.A., FORSTER R.R., GRISWOLD C.E., 1991 - Spinneret morphology and the phylogeny of haplogyne spiders (Araneae, Araneomorphae). - Am. Mus. Novit. 3016: 1-73.

RICHTER C.J.J., 1970 - Morphology and Function of the Spinning Apparatus of the Wolf Spider Pardosa amentata (Cl.) (Araneae, Lycosidae). - Z. Morph. Tiere 68: 37-68.

SELDEN P.A., SHEAR W.A., SUTTON M.D., 2008 - Fossil evidence for the origin of spider spinnerets, and proposed arachnid order. - PNAS 105: 20781-20785.

SHEAR W., PALMER J., CODDINGTON J.A., BONAMO P., 1989 - A Devonian spinneret: early evidence of spiders and silk use. Science 246: 479-481.

SUTHERLAND T.D., YOUNG J.H., WEISMAN S., HAYASHI C. Y., MERITT D.J., 2010 - Insect silk: One name, many materials. - Annu. Rev. Entomol. 55: 171-188.

TOWNLEY M.M., HORNER N.V., CHERIM N.A., TUGMON C.R., 1991 Selected aspects of spinning apparatus development in Araneus cavaticus (Araneae, Araneidae). - J. Morphol. 208: 175-191.

TOWNLEY M.A., TILLINGHAST E.K., 2003 - On the use of the ampullate gland silks by wolf spiders (Araneae, Lycosidae) for attaching the egg sac to the spinnerets and a proposal for defining nubbins and tartipores. - J. Arachnol. 31: 209-245.

TOWNLEY M.A., TILLIGHAST E.K., 2009 - Developmental changes in spider spinning fields: a comparison between Mimetus and Araneus (Araneae: Mimetidae, Araneidae). - Biol. J. Linn. Soc. 98: 343-383.

TREMBLAY M.L, XU L., LEFÈVRE T., SARKER M., ORRELL K.E., LECLERS J., MENG Q., PÉZOLET M., 2015 - Spider wrapping silk fibre architecture arising from its modular soluble protein precursor. - Sci. Rep. 5:11502.

UBICK D., 2005 - Segestriidae. In: UBICK D., PAQUIN P., CUSHING P.E., ROTH V., (Eds.), Spiders of North America: an identification manual. - Am. Arachnol. Soc.: 219-220.

WALTER A., ELGAR M.A., BLISS P., MORITZ R.F.A., 2008 - Wrap attack activates web-decorating behavior in Argiope spiders. Behav. Ecol. 19: 799-804.

WHITEHEAD W.F., REMPEL J.G., 1959 - A study of the musculature of the black widow spider Latrodectus mactans (Fabr.). - Can. J. Zool. 37: 831-870.

WORLD SPIDER CATALOG, 2016 - World Spider Catalog, version 17.5. Natural History Museum Bern. Available from: http://wsc.nmbe.ch Accessed: 2/9/2016.

YOSHICURA M., 1955 - Embryological studies on the liphistiid spider Heptathela kimurai. - Kumamoto J. Sci. Ser. B 2/3: 41-48. 